\title{
HOSPITAL TOPICS
}

\section{Results of a General Hospital Coronary Care Service}

\author{
B. L. PENTECOST,* M.D., M.R.C.P. ; N. M. C. MAYNE, $\dagger$ M.D., M.R.c.P.
}

Brit. med. F., 1968, 1, 830-833

An appreciation of the high incidence of arrhythmias during the first 48 hours after acute myocardial infarction and improved techniques of resuscitation have led to the creation of coronary care units. Their value in the routine management of this condition has been established (Lawrie et al., 1967 ; Restieaux et al. 1967), but experience is required in simple units suitable for application on a wide scale. It is important to determine - hether a relatively inexpensive unit without special resident medical staff and with a minimum of monitoring equipment -ill yield useful results in terms of successful resuscitation and Datient management.

This paper describes the first year's operation of a coronary care service in a general hospital and compares its results with those of earlier series.

\section{Organization}

The structure and organization of this unit have been described elsewhere (Pentecost et al., 1967). In brief the unit is a five-bedded open ward with a total nursing staff of eight and no resident medical officer. All patients admitted to the General Hospital with a diagnosis of acute myocardial infarcton within the preceding 48 hours entered the unit for three days, after which, if no complications were encountered, they were transferred to a medical ward. A few patients admitted to the hospital more than $\mathbf{4 8}$ hours after infarction were treated In the unit because either cardiac failure or arrhythmias were present. Throughout the period of admission each patient remained under the care of his own consultant physician and that consultant's junior staff, but cardiac pacemaking and other special procedures were undertaken by a member of the cardiac department of the hospital. Each patient's electrocardiogram was displayed on an oscilloscope which was monitored by the nursing staff; rate-dependent warning systems were seldom used. Permanent recordings of any arrhythmias were made with a single channel recorder.

\section{Patients}

During the 12 months following 26 October 1966317 patients were admitted to the coronary care unit, of whom 232 were eventually found to have suffered an acute myocardial infarction. The diagnostic criteria for acute myocardial infarction were: (1) the appearance of pathological $\mathrm{Q}$ waves in association with elevation of the $S T$ segment and subsequent $T$-wave Inversion (161 cases); (2) suggestive changes in the ST segment and $T$ wave accompanied by a transient rise in the serum aspartate aminotransferase $>45$ Reitman and Frankel units (58 cases); and (3) the E.C.G. pattern of left bundle-branch block with enzyme changes (11 cases). In two patients death occurred before a full electrocardiogram could be taken and the diagnosis was confirmed at necropsy. Of the 232 patients with acute Infarction 196 were men (average age 57 years) and 36 women (average age 61.1 years). Table I shows that no age limit was imposed on patients considered for admission to the unit. The final mortality rate refers to those patients who died before dis-

- Consultant Physician, the General Hospital, Birmingham 4. + Senior Registrar, the General Hospital, Birmingham 4. charge from hospital, which was usually after a total of four weeks' stay.

TABLE I.-Age and Mortality of 232 Patients Admitted to the Coronary

\begin{tabular}{c|c|c} 
& \multicolumn{3}{|c}{ Care Unit } \\
\hline Age & No. of Patients & No. of Deaths \\
\hline $30-39$ & 60 & $1(17 \%)$ \\
$40-49$ & 49 & $6(15 \%)$ \\
$50-59$ & 90 & $11(12 \%)$ \\
$60-69$ & $72(24 \%)$ \\
$70-79$ & 79 & $6(32 \%)$ \\
$80-89$ & $5(40 \%)$ \\
\hline Total & 232 & $43(18.5 \%)$ \\
\hline
\end{tabular}

The delay between onset of infarction as judged by the beginning of symptoms and the time of admission is shown in Table II : $44 \%$ of patients were admitted within three hours, $66 \%$ within six hours, and $79 \%$ within 12 hours of the onset of symptoms. The majority of patients admitted in the first three hours to this hospital entered as the result of some emergency service rather than from general-practitioner referral. The mortality rate after infarction was highest in those admitted within three hours of the initial symptoms and gradually fell subsequently apart from the group admitted after 48 hours.

\begin{tabular}{c|c|c} 
TABLE II.-Delay Between Onset of Symptoms and Admission to Unit \\
\hline Delay (hours) & No. of Patients & Deaths \\
\hline $0-3$ & 103 & $24(23 \%)$ \\
$4-6$ & 49 & $9(18 \%)$ \\
$7-12$ & 32 & $4(13 \%)$ \\
$13-24$ & 22 & $3(14 \%)$ \\
$25-48$ & 10 & $0(0 \%)$ \\
$>48$ & 16 & $3(19 \%)$ \\
\hline Total & 232 & 43 \\
\hline
\end{tabular}

\section{Arrhythmias}

No attempt has been made to assess the incidence of all transient arrhythmias-for example, occasional ventricular ectopic beats and short bursts of ventricular tachycardia-since our techniques of monitoring and recording were not adequate for this purpose. Table III gives the incidence of major arrhythmias.

TABLE III.-Incidence of Major Arrhythmias

\begin{tabular}{|c|c|c|}
\hline Rhythm & Patients & Deaths \\
\hline $\begin{array}{lll}\text { Ventricular tachycardia } & \ldots & \ldots \\
\text { Ventricular fibrillation } & & \end{array}$ & 14 & $\begin{array}{r}5 \\
18\end{array}$ \\
\hline Atrioventricular block $\left\{\begin{array}{l}\text { Second degree } \\
\text { Complete }\end{array}\right.$ & $\begin{array}{r}7 \\
12\end{array}$ & $\begin{array}{l}0 \\
4\end{array}$ \\
\hline 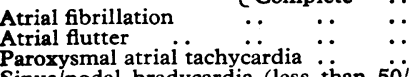 & $\begin{array}{r}23 \\
4 \\
5\end{array}$ & $\begin{array}{l}7 \\
2 \\
0\end{array}$ \\
\hline $\begin{array}{c}\text { Sinus/nodal bradycardia (less than } 50 / \\
\text { min.) }\end{array}$ & 13 & 0 \\
\hline
\end{tabular}

Ventricular extrasystoles were treated if more frequent than one in ten beats, if multifocal, or if of the $R$ on $T$ pattern Treatment was attempted in 33 patients, usually with intravenous lignocaine $(1 \mathrm{mg} . / \mathrm{kg}$.) or occasionally intravenous propranolol (1-2 mg.). Therapy was successful in abolishing or 
substantially reducing the frequency of ectopic beats in about $70 \%$ of patients. Ventricular tachycardia was observed in 14 patients; in three spontaneous reversion to sinus rhythm occurred within five minutes. In five patients there was rapid progression from ventricular tachycardia to fibrillation. This was corrected by direct current countershock in all cases, but only two of the group survived to be discharged from hospital. Three patients were converted to sinus rhythm with lignocaine ; in three others lignocaine failed and reversion to sinus rhythm was accomplished with countershock. In this last group two patients subsequently died, one of multiple emboli and the other in cardiac failure.

Primary ventricular fibrillation is defined as that occurring in an otherwise uncomplicated infarction, and the success rate of resuscitation was high when this occurred within the unit (Table IV). In all cases the initial episode happened within the first 24 hours of admission. Three patients experienced multiple episodes of ventricular fibrillation over 48 hours. Primary fibrillation occurring later in the patient's admission after removal to the ward, however, carried a poor prognosis. Though initial resuscitation with restoration of normal rhythm and blood pressure was often successful, there was usually a failure to maintain either normal rhythm or vital functions and death nccurred within 24 hours. Late and unexpected ventricular fibrillation was encountered in three patients, two of whom died. A further four patients died in their sleep, being at the time free from cardiac failure, and must be suspected of having died of an arrhythmia (Table V). Only one of the seven could be said to have had a previously uncomplicated course, but in none had there been clinical evidence of failure or obvious warning arrhythmia before death. In three patients evidence of fresh infarction was obtained at necropsy, and in the survivor there was electrocardiographic and enzymatic evidence of an extension of the previous infarction.

Secondary ventricular fibrillation may be defined as that accompanying an already compromised circulation as in shock or cardiac failure. The results of attempted resuscitation in the unit were poor. The incidence of ventricular fibrillation as a terminal event in heart failure after leaving the unit was not known, since monitoring was not extended to this period.

TABLE IV.-Ventricular Fibrillation

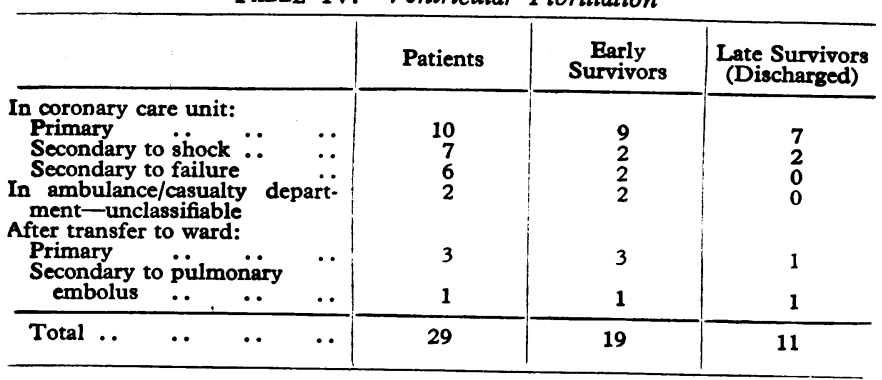

TAвLв V.-Late Unexpected Cardiac Arrest

\begin{tabular}{|c|c|c|c|c|c|}
\hline Patient & Age & Mode of Death & Day & $\begin{array}{l}\text { Previous Complica- } \\
\text { tions or Disease }\end{array}$ & Necropsy \\
\hline A & 54 & $\begin{array}{l}\text { Ventricular } \\
\text { fibrillation }\end{array}$ & 4 & Coarctation of aorta & None obtained \\
\hline B & 68 & Died in sleep & 11 & $\begin{array}{l}\text { Diabetes. Second- } \\
\text { degree block. Atrial } \\
\text { flutter. Cardiac } \\
\text { failure }\end{array}$ & None obtained \\
\hline C & $72^{\circ}$ & Died in sleep & 28 & $\begin{array}{l}\text { Ventricular tachy- } \\
\text { cardia. Atrial fibril- } \\
\text { lation. Cardiac } \\
\text { failure }\end{array}$ & Fresh infarction \\
\hline D & 66 & $\begin{array}{l}\text { Ventricular } \\
\text { fibrillation }\end{array}$ & 18 & $\begin{array}{l}\text { Cardiac failure. } \\
\text { Right bundle-branch } \\
\text { block }\end{array}$ & Fresh infarction \\
\hline $\mathrm{E}$ & 60 & Died in sleep & 15 & $\begin{array}{l}\text { Cardiac failure. } \\
\text { Ventricular ectopic } \\
\text { beats }\end{array}$ & Fresh infarction \\
\hline $\mathbf{F}$ & 56 & Died in sleep & 18 & $\begin{array}{l}\text { Previous infarction. } \\
\text { Cardiac failure. } \\
\text { Ventricular ectopic } \\
\text { beats }\end{array}$ & None obtained \\
\hline G & 66 & $\begin{array}{l}\text { Ventricular } \\
\text { fibrillation }\end{array}$ & 14 & None & $\begin{array}{l}\text { Survival. E.C.G. } \\
\text { showed exten- } \\
\text { sion of infarc- } \\
\text { tion }\end{array}$ \\
\hline
\end{tabular}

First-degree atrioventricular block was extremely common after inferior myocardial infarction-too common to be used as a premonitory sign of more serious conduction defect. Second-degree block, either occasional dropped beats or a fixed two-to-one atrioventricular block, was seen in eight patients, all of whom reverted to sinus rhythm without progression to complete block. Two developed slow ventricular rates of less than 40 per minute which responded to either atropine or Saventrine (isoprenaline hydrochloride). Second-degree block was not found to be permanent and seldom lasted more than 72 hours.

Twelve patients were found to develop complete heart block: eight on day 1 , two on day 2 , one on day 3 , and one on day 4 . In two cases the rhythm was present at the time of their arrival in the unit, and in four Stokes-Adams attacks were encountered. There was seldom a warning of impending complete block apart from the commonly encountered prolonged $P-R$ interval. In. one patient a progressively slowing sinus bradycardia which did not respond to atropine required to be paced and complete block developed subsequently. In two patients the ventricular rate was around 45 per minute with a high ventricular pacemaker ; treatment with oral isoprenaline raised the ventricularate to about 60 per minute and both patients survived (Table VI). No treatment was offered in the case of one elderly patient with a long history of congestive failure. The remainder had slower ventricular rates, transvenous pacing with a fixedrate pacemaker being instituted; six of the nine survived. One of the three deaths was due to unresponsive asystole occurring 10 . days after the initial block, and two occurred in patients whose shock and cardiac failure did not respond to conventional therapy, complete block developing as a terminal event.

TABLE VI.-Treatment of Complete Heart Block

\begin{tabular}{|c|c|c|c|c|c|c|}
\hline \multicolumn{5}{|c|}{ Treatment } & \multirow{2}{*}{$\begin{array}{c}\text { No. of Cases } \\
\begin{array}{c}9 \\
2 \\
1\end{array}\end{array}$} & \multirow{2}{*}{$\begin{array}{c}\text { No. of Survivors } \\
\begin{array}{c}6 \\
2 \\
0\end{array}\end{array}$} \\
\hline $\begin{array}{l}\text { Internal pacing } \\
\text { Isoprenaline } \\
\text { None . . } \\
\end{array}$ & $\because$ & $\ddot{0}$ & $\ddot{0}$ & $\begin{array}{l}. . \\
. . \\
\end{array}$ & & \\
\hline Total & .. & $\cdots$ & $\cdots$ & . & 12 & 8 \\
\hline
\end{tabular}

Atrial fibrillation or flutter was treated with digitalis, and two patients with paroxysmal atrial tachycardia responded to carotid sinus massage. It was seldom necessary to treat nodal or sinus bradycardia ; but occasionally, when hypotension, pallor, and sweating appeared, the process was reversed by administering intravenous atropine.

Ventricular asystole occurred in six patients, all of whom had previously shown evidence of cardiac failure; though two were temporarily resuscitated, both died within the next 24 hours.

\section{Shock}

The condition of severe hypotension (systolic pressure on auscultation less than $80 \mathrm{~mm}$. $\mathrm{Hg}$ )-profound peripheral vasoconstriction and mental confusion-was encountered in 23 patients.

In five an underlying arrhythmia was detected, and its correction resulted in haemodynamic improvement. The arrhythmias. encountered were atrial flutter, atrial fibrillation, sinus bradycardia, ventricular tachycardia, and complete heart block. In the remainder the standard therapeutic routine which evolved during the course of the year consisted of these sequential steps (Table VII): (1) treatment with head-down posture, digitalis, and oxygen ; (2) intravenous metaraminol (Aramine) (1-2 mg. initially); and (3) phenoxybenzamine $(1 \mathrm{mg} . / \mathrm{kg}$. body weight intravenously), with expansion of the circulating volume with $5 \%$ dextrose. The central venous pressure was monitored during the procedure, a progressive rise in venous pressure being taken as an indication for discontinuing the infusion.

Sudden ventricular asystole was a common mode of death in cardiogenic shock even after apparent clinical improvement. Asystole was preceded by complete atrioventricular block in 
two patients and was resistant to electrical stimulation of the myocardium. In a further two patients a catheter pacemaker was introduced into the right ventricle within two minutes of the onset of asystole, but on both occasions mechanical contraction failed to follow electrical stimulation.

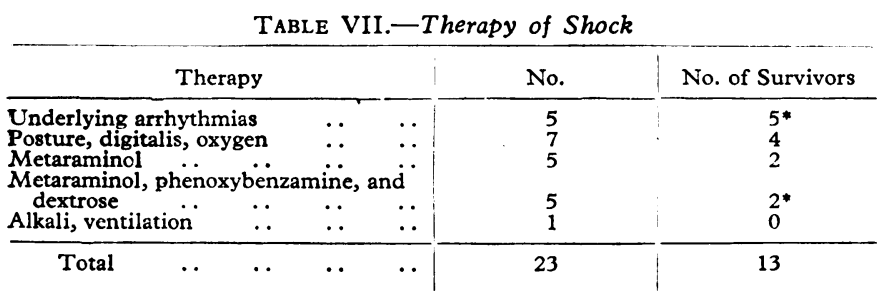

* Includes one patient who subsequently died after recovery from the shocked state.

On considering the clinical condition of the 43 patients who died it was apparent that shock and cardiac failure were the main causes of death (Table VIII). Asystole was seen only in patients who had previously been in failure at some stage, though at the onset of asystole the symptoms of failure appeared to have been improved by therapy.

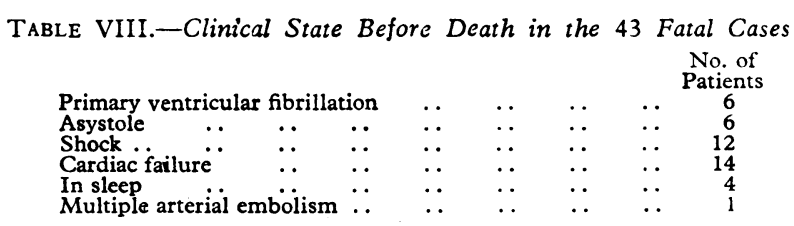

\section{Discussion}

It was impossible to evaluate a unit by simple consideration of the overall mortality rate (Oliver et al., 1967). Details of staffing and resuscitative procedures, definition of infarction with analysis of the relative frequency of subendocardial and full-thickness lesions, delay before admission, and age of patients must all be considered in an assessment of the unit's efficiency. There is good evidence in the data presented here that the unit described has a high intake of acute admissions. Forty-four per cent. of patients were admitted within three hours of the onset of symptoms, and the acute nature of the cases is reflected in the high mortality in this group (23\%). This finding confirms the experience of Lawrie et al. (1967). A high proportion of patients admitted during the first few hours of their illness will increase the overall mortality, whereas admitting patients several hours after infarction produces a lower mortality during the period of hospital admission (Lown et al., 1967).

The incidence of ventricular fibrillation occurring within the unit $(10 \%)$ is similar to that encountered by other coronary care units dealing with the acute situation (Julian et al., 1964, $7 \%$; Lawrie et al., 1967, 11\% ; Restieaux et al., 1967, $10 \%)$. The overall survival rate from this arrhythmia was $38 \%$, compounded of a $70 \%$ survival after primary ventricular fibrillation and $15 \%$ when the arrhythmia complicated shock or cardiac failure. This successful resuscitation rate is comparable to that of more complex units; Lawrie et al. (1967) reported a $52 \%$ survival after ventricular fibrillation, but the present series contains several patients over the age of 70 , which adversely affects the mortality figure. We share the general view that immediate defibrillation without delay for endotracheal intubation and other supportive procedures represents the best chance of successful electrical reversion to sinus rhythm. It is therefore obligatory to train nurses not only in the recognition of arrhythmias but to a standard permitting the use of direct-current countershock. No electrical cardioversion was attempted by the nursing staff during the period under review, but during the subsequent three months this procedure has been successfully undertaken by nurses working within the unit. Inevit- ably there is a delay of a few seconds while the condenser is charged, and occasionally the patient is found to revert to sinus rhythm under the influence of external cardiac massage alone.

Late and unexpected cardiac arrest in seven patients represented a failure in patient monitoring. However, though the arrhythmia was unexpected an examination of the history of each patient showed a high incidence of cardiac failure and other complications in the early stages of the infarction. Necropsy on three of six patients showed evidence of fresh haemorrhagic infarction, and the surviving patient had clear evidence of an extension of the infarcted area, electrocardiographically and enzymatically. It is of interest that, although all three patients developing late ventricular fibrillation were initially resuscitated, only the patient with a previously uncomplicated course and no evidence of cardiac enlargement survived the episode. It would seem that prolonged monitoring after discharge from the unit into a general ward is unlikely to be very profitable in terms of reducing mortality (Lawrie et al., 1967), since late arrest seems to occur in patients with a poor prognosis from the degree of myocardial damage.

Though supraventricular tachycardias were commonly encountered $(14 \%)$ there was a low incidence of paroxysmal atrial tachycardia $(2 \%)$ when compared with other series (Jewitt et al., 1967, 7\% ; Julian et al., 1964, 4\%). No doubt this finding may reflect inadequate data-recording in our own series. However, we have not been impressed with the frequent need for direct-current countershock in the management of supraventricular tachycardias. Most cases responded to digitalis therapy alone, and paroxysmal atrial tachycardia and flutter were occasionally responsive to carotid sinus massage.

With increasing experience we have tended to pace all cases of complete heart block. Second-degree block has not been of value as a warning of impending complete block, and we have not felt justified in inserting catheter pacemakers into all patients with a prolonged $\mathrm{P}-\mathrm{R}$ interval. The onset of complete atrioventricular block, often accompanied by syncope or cardiac failure, was usually sudden, and for this reason rapid catheterization of the right ventricle was undertaken from the antecubital fossa rather than via the jugular vein. Patients when paced nearly always showed substantial clinical improvement, but, as with all arrhythmias, it was the degree of muscle injury which determined the outcome once pacing was established. All but one patient returned to sinus rhythm, and complete block was never permanent. It was seldom necessary to pace for more than 72 hours before there was a return of sinus rhythm, but there were occasional episodes of complete block after this time; for this reason the catheter pacemaker was left in situ for 10 days to two weeks after its initial introduction. In spite of occasional technical failures the presence of a mobile image intensifier within the unit has been advantageous. It was of considerable value in reducing the risk involved in transporting patients in complete heart block between the unit and the department of radiology and avoided unnecessary delay in the introduction of a pacemaker catheter.

The importance of searching for an underlying arrhythmia in patients in shock was obvious, and the results of rhythm correction were gratifying. It was found that, although shocked patients occasionally responded to the various therapeutic regimens described with a rise in arterial pressure, a fall in central venous pressure, and some improvement in the accompanying acidosis, it remained common for asystole to occur without warning. Asystole was resistant to pacing on the four occasions that this was attempted. At necropsy the area of infarction was extremely large, though previous detailed pathological studies have shown no close correlation between shock and massive infarction (Rosenberg and Malach, 1960 ; Kurland et al., 1965). If there is such a correlation it would greatly diminish the chances of therapeutic advance in this direction.

Acute myocardial infarction is an extremely common emergency in general hospitals, with a high incidence of acute medical admissions. It is important to ensure that a coronary care 
unit, as with any intensive care unit, is open as a facility to all physicians in the hospital (B.M.A., 1967). It should not be seen as an interference in the highly individual management of the clinical situation by each doctor, but merely a setting where facilities for early detection of arrhythmias and emergency resuscitation are freely available. The satisfactory results obtained in this unit lead us to feel that there is little need for a resident physician provided that the nursing staff can be trained to a sufficient standard and that all resident medical officers are familiar with the techniques involved in resuscitation. Similarly, it is not necessary for the unit to be very complex in design or equipment to effect a satisfactory service.

\section{Summary}

A coronary care service available to all physicians within a general hospital is described. During the first year over 300 patients, of whom 232 had suffered an acute myocardial infarction, passed through the unit, which was simple in design and largely dependent on nursing staff for its immediate management. The results obtained suggest that this type of organization provides a satisfactory standard of patient-care.

\section{REFERENCES}

B.M.A. (1967). Planning Unit Report, No. 1. Intensive Care. London. Jewitt, D. E., Balcon, R., Raftery, E. B., and Oram, S. (1967). Lancet, 2, 734.

Julian, D. G., Valentine, P. A., and Miller, G. G. (1964). Amer. F. Med., $37,915$.

Kurland, G. G., Weingarten, C., and Pitt, B. (1965). Circulation, 31, 646.

Lawrie, D. M., et al. (1967). Lancet, 2, 109.

Lown, B., Fakhro, A. M., Hood, W. B., and Thorn, G. W. (1967). f. Amer. med. Ass., 199, 188.

Oliver, M. F., Julian, D. G., and Donald, K. W. (1967). Amer. F. Cardiol., 20, 465 .

Pentecost, B. L., Mayne, N., and Lamb, P. (1967). Brit. med. 7., 3, 298. Restieaux, N., et al. (1967). Lancet, 1, 1285.

Rosenberg, B. A., and Malach, M. (1960). Amer. F. Cardiol., 6, 272.

\section{CONTEMPORARY THEMES}

\section{Transplantation of Organs}

In a written Parliamentary answer in the House of Commons on 25 March the Minister of Health said that he had received a report on the conclusions of a conference on the transplantation of organs held at the Ministry of Health on 6 March. "These conclusions, which seem right to me," the Minister said, "are being communicated to hospital medical staff concerned. The conference wished to meet again to consider the safeguards which would be needed, in any amendment of the Act, for people who would object to the removal of organs from their own bodies after death or from those of their close relatives. I intend to await the outcome of this further meeting before reaching a view on the need for legislation and the form it might take.

"The conclusions of the meeting held on 6 March are:

"The practitioners engaged in kidney transplantation explained that this work is now being held up by the difficulty of obtaining sufficient cadaver kidneys. This was partly because of the difficulty of making the necessary inquiries of relatives in the time available, partly because of lack of co-operation from medical colleagues in charge of potential donors before death on whom the task of making such inquiries would fall. They would like the Human Tissue Act to be amended to dispense with the need for inquiries of the relatives, leaving it to objectors to make their views known in advance.

"It was pointed out that the removal of organs after death can obscure signs of forensic importance. Recognizing that it would not always be possible to consult the coroner or procurator-fiscal in advance of removal, a coroner might be prepared to allow organs to be removed provided that the surgeon effecting removal would undertake to note and report any such signs. The conference endorsed the importance of co-operation between surgeons and coroners or procurators-fiscal in this respect.

"The conference recognized that the public, and nurses also, were uneasy about the possibility that organs might be removed prematurely. The conference agreed that no attempt should be made to lay down a legal definition of death or rules which doctors should observe in reaching what must be a clinical decision; but that to allay disquiet vital organs should not be removed until spontaneous vital functions had ceased and two doctors, each independent of the transplantation team and one of them being at least five years qualified, had certified that this condition was irreversible. It was moreover essential that the doctors concerned should explain the matter adequately to the nursing staff concerned, especially in those cases where the patient's vital functions were being maintained by artificial means.

"The conference accepted that in the absence of cadaver kidneys the taking of single kidneys from living donors might still be justifiable, but emphasized that there were special considerations affecting young persons under 18 which made it especially difficult to ensure that consent was free from outside influence.

"The conference accepted that S.1(2) of the Human Tissue Act restricts the availability of donor organs to an extent which prevents the treatment of patients who will otherwise die.

But the conference recognized that there are people, including the members of certain religious groups, who would object to the removal of organs from their own bodies after death or from those of their close relatives. The conference did not reach firm conclusions on the safeguards which would be required for these people, and wished to meet again to consider them." 